\title{
ANÁLISE TEMPORAL DA COBERTURA VEGETAL DO PARQUE NACIONAL DA SERRA DO CIPÓ(MG) UTILIZANDO A TÉCNICA DE NDVI
}

Glória Ramos Soares*

\section{Resumo}

Mudanças na paisagem, como a destruição de habitats e fragmentação da paisagem, estão entre as pressões ambientais mais severas à biodiversidade. Existem diversas técnicas que auxiliam na identificação destas transformações da paisagem como comparação pós-classificação, diferença e razão de imagem, diferença de índice de vegetação, análises de componentes principais e análise de vetor de mudança. O NDVI identifica o grau de verde da superfície terrestre ocupada pela vegetação, resultado da combinação dos níveis de reflectância nas imagens de satélite. O objetivo deste artigo foi avaliar e quantificar mudanças na paisagem ocorridas no Parque Nacional da Serra do Cipó (MG) nos últimos 30 anos através de imagens de satélite Landsat de períodos distintos. Dos 351.445 pixels classificados na imagem da diferença NDVI 2011 - NDVI 1985, 26.853 representaram regeneração contra 23.964 de desmatamento. Cerca de $85 \%$ da paisagem não sofreu alteração (300.638 pixels) indicando que a criação do PARNA Cipó foi eficiente na conservação da vegetação. A utilização desta técnica possibilita retratar a condição de degradação sofrida pelo parque ao longo dos 26 anos de criação por retirada de cobertura vegetal, principalmente nas bordas, e ocorrência de processos erosivos.

Palavras-chave:Mudança da paisagem. NDVI. Ecologia da paisagem. Cobertura vegetal.

\footnotetext{
*Mestranda em Análise e Modelagem de Sistemas Ambientais pelo IGC/UFMG.biogloria@yahoo.com.br) 


\section{1- INTRODUÇÃO}

A Ecologia da Paisagem foi, pela primeira vez, introduzida pelo então geógrafo alemão Carl Troll, em 1939 (Troll, 1939). Troll enfatizou a necessidade da fusão de duas importantes disciplinas, Ecologia e Geografia, com o intuito de integrar a geosfera, a biosfera e a noosfera (Soares Filho, 1998). Por definição, Forman \&Godron (1986) definem que Ecologia da Paisagem é o estudo da relação entre os elementos estruturais e suas funções e modificações na composição da paisagem ao longo do tempo. Já Turner (1989) define como uma área do conhecimento que dá ênfase as escalas espaciais amplas e aos efeitos ecológicos do padrão de distribuição espacial dos ecossistemas.

Como a paisagem está constantemente em mudança, sua estrutura e composição podem alterar drasticamente ao longo do tempo ocasionando em novos arranjos e interações do ecossistema (Forman \&Godron, 1986). Frente a estas mudanças, o estudo da paisagem tornou-se uma importante ferramenta para a conservação do meio ambiente permitindo a descrição, compreensão e previsão das alterações do meio. Isto fornece suporte à gestão dos recursos naturais em áreas de elevado valor ecológico e/ou de peculiar sensibilidade ambiental (Honrado et al, 2012 p. 2), possibilitando ainda a análise dos remanescentes de vegetação nativa existentes.

Mudanças na paisagem, como a destruição de habitats e fragmentação da paisagem, estão entre as pressões ambientais mais severas à biodiversidade (Marini-Filho \& Martins, 2000). Estes autores afirmam ainda que espécies com distribuições restritas são eliminadas e que as fragmentações impedem espécies de grande porte de manter populações viáveis, por não conseguirem distribuir-se de maneira espaçada. Estima-se que em poucas décadas, diversas espécies poderão ser extintas devido à perda da biodiversidade, principalmente as endêmicas, que só ocorrem em ambientes específicos aos quais estão bem adaptadas (Sugieda\&Schaalmann, 2009).

A detecção destas mudanças na paisagem, através de imagens de satélite, pode ser realizada pelo reconhecimento das alterações nos padrões característicos nas imagens, num espaço de tempo. Existem diversas técnicas que auxiliam na identificação destas transformações da paisagem como comparação pós-classificação, diferença e razão de imagem, diferença de índice de vegetação, análises de componentes principais e análise de vetor de mudança (Singh, 1989, p. 990). Singh (1989, p. 990) cita ainda duas abordagens básicas para a 
detecção da mudança: (i) uma análise comparativa de classificações em diferentes datas e (ii) análise simultânea de dado multitemporal.

A utilização de imagens de sensoriamento remoto orbital em prol da conservação possibilita uma gama de vantagens. Dentre estas pode-se citar a facilitação na análise da dinâmica de diversos fenômenos espaciais, percorrendo as escalas local, regional e global, justamente devido a coleta repetitiva de dados multiespectrais (Soares Filho, 1998, p.62). Outra vantagem elecanda por este mesmo autor diz respeito a essência digital das imagens. Elas possibilitam a aplicação de algoritmos computacionais que realçam e classificam os padrões das imagens, produzindo índices de estrutura de paisagem que podem ser utilizados para monitorar e prever mudanças. Através dos sensores multiespectrais é possível ainda monitorar a evolução espacial e temporal das mudanças na cobertura da superfície terrestre como queimadas, desmatamentos, uso e cobertura do solo e expansão urbana.

Diante da robustez do sensoriamento remoto, este trabalho tem como objetivo avaliar e quantificar mudanças na paisagem ocorridas no Parque Nacional da Serra do Cipó (MG) nos 26 últimos anos através de imagens de satélite Landsat de períodos distintos.

\section{Caracterização da área}

Criado no ano de 1987, o Parque Nacional da Serra do Cipó - Parna Cipó (19022'01"S e 43037'10"W) está localizado na porção sul da Cadeia do Espinhaço, nos municípios de Jaboticatubas, Santana doRiacho, Morro do Pilar e Itambé do Mato Dentro, todos no interior de Minas Gerais, (Figura 1).Abrangendo uma área de 31.639,18 hectares, o PARNA Cipó é composto por áreas de Cerrado, MataAtlântica, Campo Rupestre, Matas Ciliares e Capões de Mata, possuindo em sua porção alta oquartzito onde se desenvolve o Campo Rupestre. Já em sua região de baixada, o Cerrado propriamente dito apresenta áreas abertas (campos) e matas de galeria. O clima predominante naárea é o tropical de altitude do tipo Cwb, com verões frescos e com estação seca marcante. Já orelevo apresenta características montanhosas, com altitude variando entre 800 e 1400 metros(ICMBIO, 2009). 


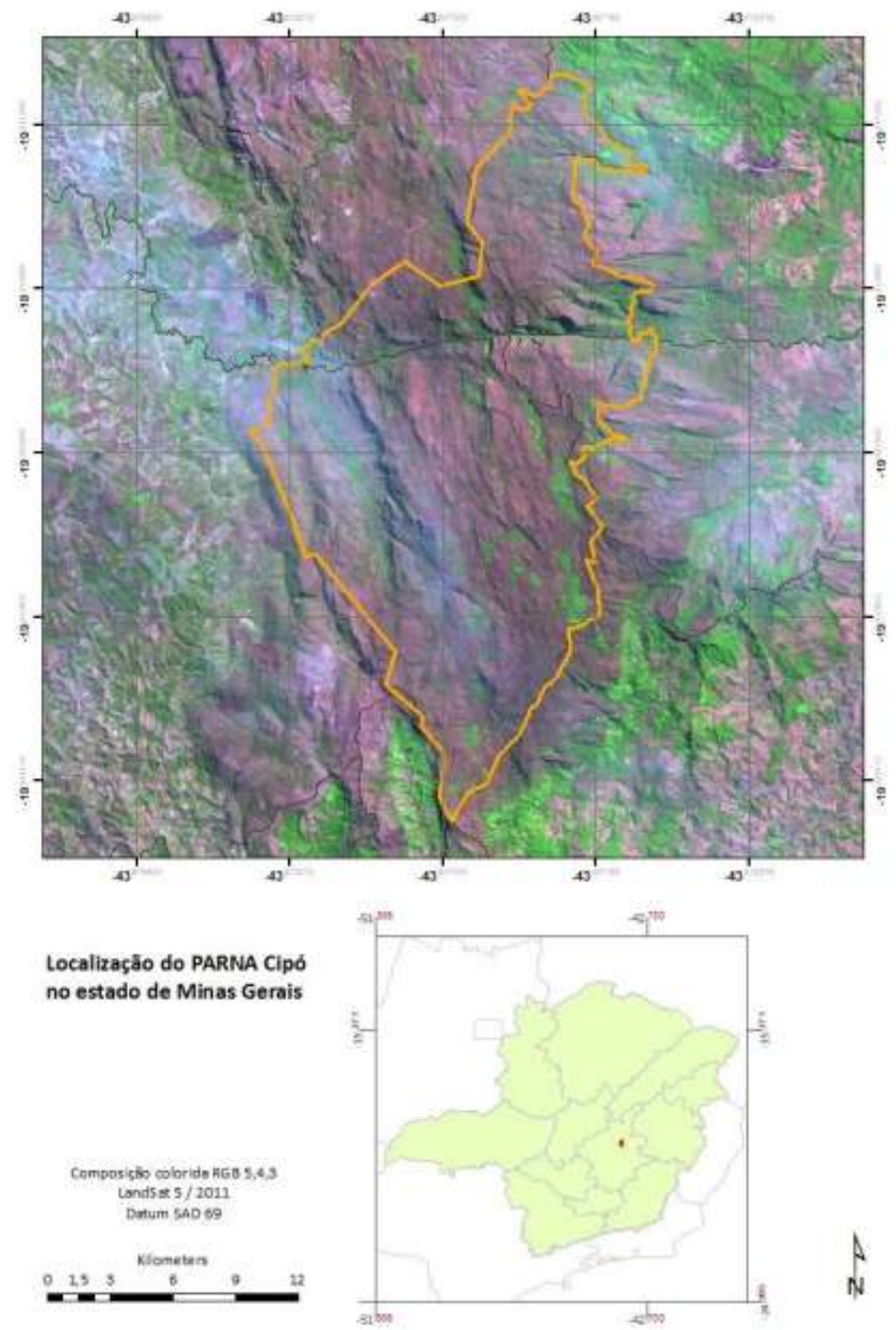

Figura 1: Localização da área de estudo.

\section{Metodologia}

Para a análise dos índices de vegetação no PARNA Cipó foram utilizadas duas imagens orbitais no sensor TM acoplado ao satélite LANDSAT - 5 de órbita 218 ponto 074 e 073 . As imagens foramadquiridas através do site do Instituto Nacional de Pesquisas Espaciais - INPE (http://www.dgi.inpe.br/CDSR/) correspondentes ao mês de agosto/1985 e setembro/2011. Estasimagens cobrem os municípios de Jaboticatubas, Santana do Riacho, Itambé do Mato Dentro e Morrodo Pilar. 
As imagens foram processadas no software Environment for VisualizingImages ENVI 4.7 onde foirealizada a junção das bandas em um único arquivo, denominado empilhamento, de maneira quepudesse ser facilmente manipulado. As bandas utilizadas foram 1, 2, 3, 4, 5 e 7 . Foi necessário aindarealizar a correção geométrica através da ferramenta de registro Georeferencing do software ArcGis9.3 para que a imagem fosse posta em sua exata posição espacial.

De acordo com Lourenço \& Landim (2004) as imagens do satélite Landsat 5 TM, possuem características espectrais nas faixas do vermelho e infravermelho próximo permitindo sua utilizaçãoem estudos que abordem a cobertura vegetal. Afirmam ainda que na faixa do vermelho a clorofilaabsorve a energia solar ocasionando uma baixa reflectância, enquanto na faixa do infravermelhopróximo é ocasionado uma alta reflectância da energia solar incidente. Matematicamente, a aplicaçãodestes atributos gera um contraste na vegetação presente nas imagens, onde, quanto maior for estecontraste, maior será a vivacidade da vegetação na área imageada e a combinação destas duas faixasespectrais realçarão estas áreas.

Com o intuito de indentificar o grau de verde da superfície terrestre ocupada pela vegetação, calculou-se o NDVI (NormalizedDifferenceVegetation Index). Este modelo é resultado da combinaçãodos níveis de reflectância nas imagens de satélite composto pelas respostas das bandas espectrais dovermelho e do infravermelho, bandas 3 e 4 respectivamente, representado pela seguinte equação:

$$
\mathrm{NDVI}=(\mathrm{NIR}-\mathrm{RED}) /(\mathrm{NIR}+\mathrm{RED})
$$

Em que:

$$
\begin{aligned}
& \text { NDVI = NormalizedDifferenceVegetation Index } \\
& \text { NIR = Valor de reflectância na banda do infravermelho próximo (banda 4) } \\
& \text { RED = Valor de reflectância na banda do vermelho visível (banda 3). }
\end{aligned}
$$

A análise temporal de mudanças nas imagens consistiu na subtração dos índices de vegetação calculados para o ano de 1985 daqueles calculados para o ano de 2011. Os níveis de cinza nasimagens produzidas foram divididos em três classes, sendo que os divisores foram o valor de umdesvio padrão abaixo da média e de um desvio padrão acima da média, o que indica a mudançaocorrida na cobertura vegetal da terra no período analisado. Realizou-se ainda o cálculo deporcentagem destas mudanças nas imagens. 


\section{Resultados}

As imagens NDVI dos anos de 1985 e 2011 são ilustradas nas figuras 2 e 3, as quais apresentam diferenças de tonalidades, mas poucas diferenças visuais de comportamento dos alvos de acordo coma fotointerpretação. Tradicionalmente estas imagens apresentam resultados que variam de $-1 \mathrm{a}+1 \mathrm{em}$ escalas de tons de cinzas.



Figura 2: Mapa do índice de vegetação por diferença normalizada referente ao ano de 1985. 


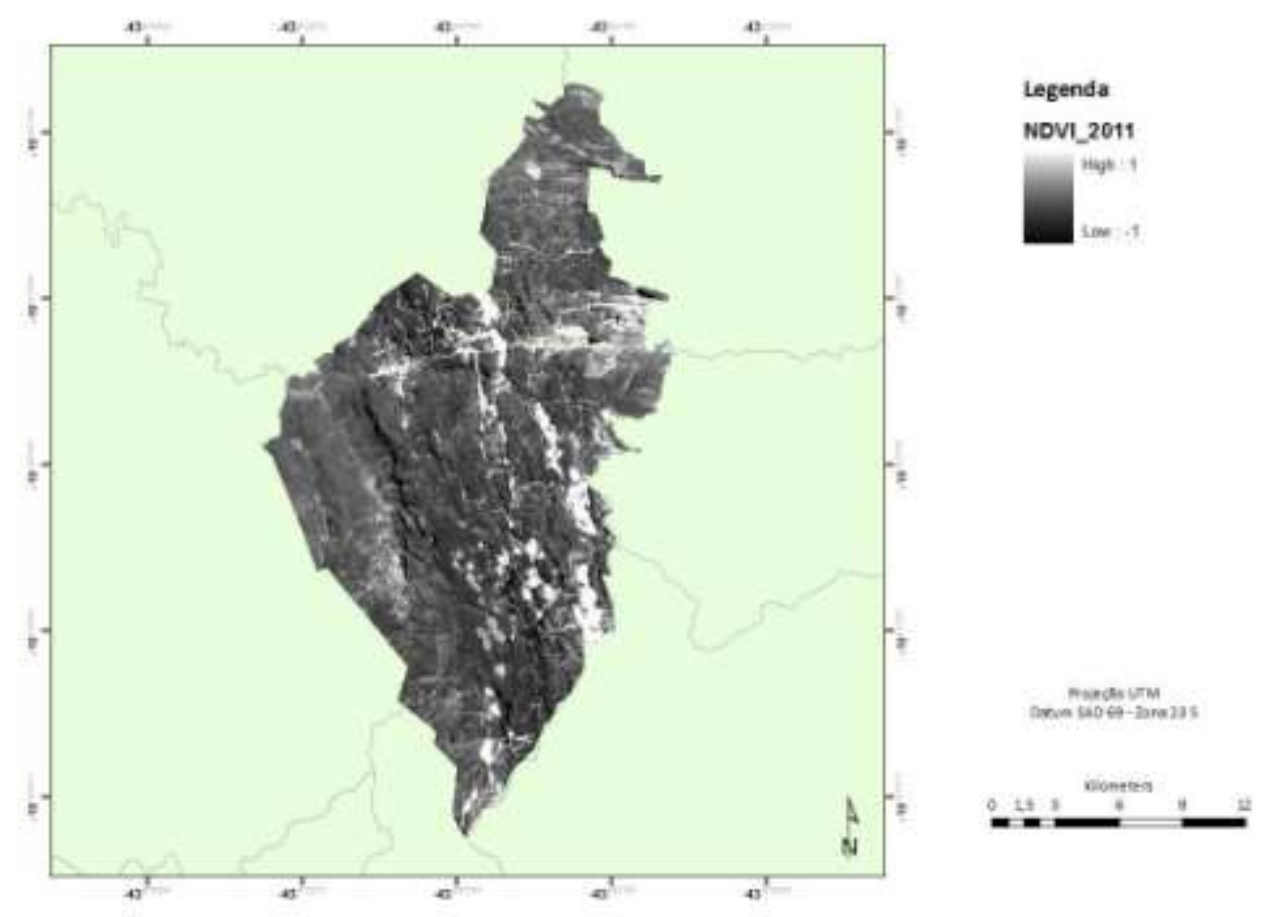

Figura 3: Mapa do índice de vegetação por diferença normalizada referente ao ano de 2011.

Uma das formas de identificar a verificação das mudanças ocorridas durante o período estudado é por meio de uma operação matemática de subtração entre os dois mapas:

DIF 11/85 = NDVI 2011 - NDVI 1985

onde NDVI 1985 é o mapa do ano de 1985 e NDVI 2011 é o mapa do ano de 2011.

A subtração da imagem de 2011 pela imagem de 1985 resultou numa imagem em tom de cinza que foi reclassificada conforme a seguinte equação:

$$
X \pm 2 * S x
$$

onde $X$ é a média, $S x$ é o desvio padrão e 2 é uma constante K positiva.

As classes foram delimitadas de acordo com os valores extraídos da subtração das imagens, sendo a $X 2,32$ e o $S x 46,60$.

O resultado é um mapa de escala contínua de valores negativos que aumenta para valores positivos, onde quanto maior for o valor positivo, maior será o ganho de NDVI, e quanto maior o valor negativo,maior será a perda de NDVI (Figura 4). As áreas com valores próximos a zero não apresentarãomudanças significativas. Deste modo, nos resultados das subtrações dos índices os valores em tornoda média até o limite de um desvio padrão indicam 
estabilidade ou não alteração da cobertura dosolo, enquanto os valores que se distanciam além do valor de um desvio padrão acima ou abaixo damédia indicam mudança.

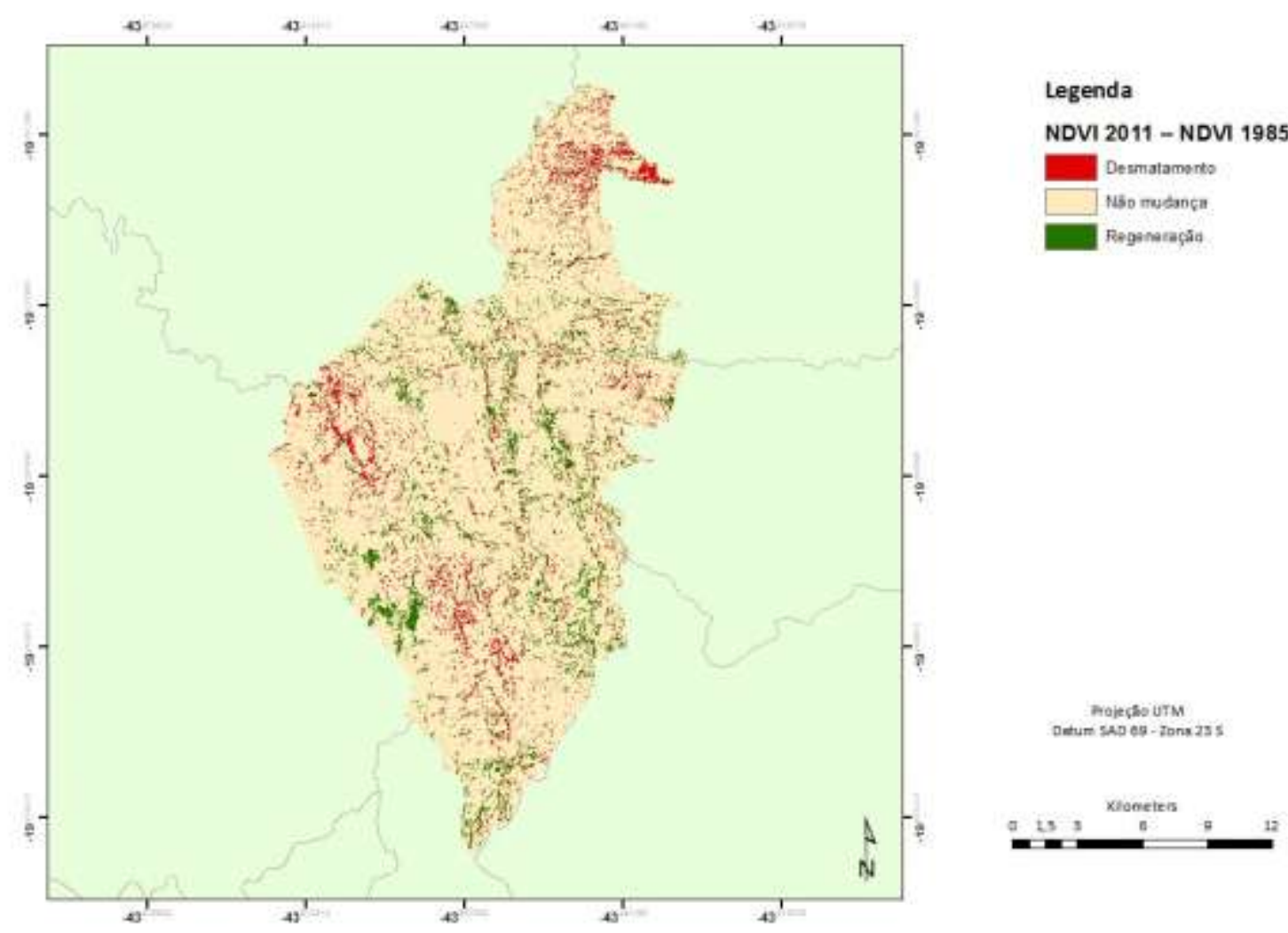

Figura 4: Mapa temático das diferenças de NDVI de 1985 para 2011.

\section{Discussão}

O processo de modelar uma paisagem, através da construção matricial ou raster, é simplificado pela compatibilidade com imagens de satélite além de ser mais fácil de lidar matematicamente (Soares-Filho et al, 2007 p. 3). Esta facilidade se deve ao fato de que cada célula do modelo possuir o mesmo tamanho e forma, resultando em uma maior capacidade analítica (por exemplo, álgebra cartográfica) e em uma tendência de ser mais rápida para avaliações de múltiplas camadas cartográficas (Soares-Filho et al, 2007 p. 3).

Atualmente existe uma variedade de índices de vegetação que auxiliam no monitoramento da cobertura vegetal. Estes são baseados em diferentes interações entre o tipo de vegetação e sua correspondente assinatura espectral. O NDVI é eficiente no monitoramento por compensar parcialmente a variação nas condições de iluminação e de topografia. Outro atributo importante na aplicação desta técnica está no mapa temático que pode ser produzido pela diferença de NDVI. Analisando a figura 4 nota-se as áreas que apresentaram cores no tom 
verde, indicando maior densidade de vegetação, por outro lado, a cor vermelha representou áreas de menor densidade de vegetação. Este tipo de análise pode e deve ser constantemente realizado pelos gestores da Unidade de Conservação identificando os locais que sofreram maior pressão, possibilitando que medidas acertadas de manejo possam ser aplicadas a fim de manter um índice de vegetação relevante no PARNA Cipó.

As principais ameaças que o parque vem sofrendo ao longo dos seus 26 anos como desmatamento, incêndios clandestinos, parcelamento desordenado do solo associado às atividades turísticas da região e plantio descontrolado da braquiária para formação de pastagem influenciaram na composição atual da vegetação. Dos 351.445 pixels classificados na imagem da diferença NDVI 2011 - NDVI 1985, 26.853 representaram regeneração contra 23.964 de desmatamento. Cerca de $85 \%$ da paisagem não sofreu alteração (300.638 pixels) indicando que a criação do PARNA Cipó foi eficiente na conservação da vegetação. A utilização desta técnica possibilita retratar a condição de degradação apelo parque ao longo dos anos por retirada de cobertura vegetal, principalmente nas bordas, e ocorrência de processos erosivos.

O cálculo de NDVI é uma técnica eficiente na análise de mudanças temporais ocorridas na cobertura vegetal, produzindo mapas que indicam condições da área com relação a vegetação. Esta técnica auxilia ainda na elaboração de mapas demonstrando a diferença entre os dados de NDVI para períodos distintos. Unidades de Conservação como o Parque Nacional da Serra do Cipó abrigam uma rica biodiversidade ambiental merecedora de proteção e monitoramento. Pressões como o avanço acelerado do turismo e questões decorrentes, como forte parcelamento do solo e abertura de vias de acesso, ameaçam progressivamente o parque sendo importante a acompanhamento da vegetação frente aos impactos antrópicos.

\section{Referências Bibliográficas}

Instituto Chico Mendes de Conservação da Biodiversidade. (ICMBIO). Plano de Manejo do Parque Nacional da Serra do Cipó. 2009.

Forman, R. T.T. \& Gordon, M. Landscape Ecology. John Wiley\& Sins. 1986.

Honrado, J.; Gonçalves, J.; Lomba, Â. \& Vicente, J. Ecologia da Paisagem e : da investigação à gestão e à conservação. Ecologia 5: 36-51. 2012.

Lourenço, R.W \& Landim, P.M.B. . Estudo da variabilidade do "Índice de vegetação por diferença normalizada/NDVI" utilizando krigagem indicativa. HolosEnvironment, v.4 (1): 38 35. 2004.

Marini-Filho, O. J. \& Martins, R.P. . Teoria de metapopulações: novos princípios na biologia da conservação. CiênciaHoje, v. 27, n. 160, p. 22-29. 2000. 
Singh, A. Digital change detection techniques using remotely-sensed data. InternationalJournalof Remote Sensing, v. 10, n. 6, p. 989-1003, 1989.

Soares Filho, B. S. Análise da Paisagem: Fragmentação e mudanças. Belo Horizonte. 1998

Soares Filho, B. S.; Cerqueira, G. C.; Araújo, W. L. \&Voll, E.. 2007. Modelagem de dinâmica de paisagem: concepção e potencial de aplicação de modelos de simulação baseados em autômato celular. Megadiversidade, v. 3 (1-2). p. 74- 86. 1998.

Sugieda, A. M. \&Schaalmann, C.T. . In: Bressan, P. M.; Kierulff, M. C. M. \&Sugieda, A. M. (eds.). Fauna ameaçada de extinção no Estado de São Paulo: Vertebrados. Fundação Parque

Zoológico de São Paulo, Secretaria do Meio Ambiente. 645p. 2009.

Troll, C. Lufbildplan and ökologischeBodenforschung. Z. Ges. Erdkunde. Berlin, v.241, n. 98. 1939

Turner, M.G. . Landscape ecology: the effect of pattern on process. AnnualReviewofEcologyandSystematic 20: 171-197. 1989. 